\title{
Profiles of Inhaled Flow from Dry Powder Inhalers in Subjects Unfamiliar with the Devices
}

\author{
Tetsuri Kondo*1, Toshimori Tanigaki ${ }^{2}$, Sakurako Tajiri ${ }^{3}$, \\ Motoki Ohe ${ }^{1}$, Makoto Hibino ${ }^{1}$ and Kenichiro Akazawa ${ }^{1}$ \\ Department of Respiratory Medicine, Shonan Fujisawa Tokushukai Hospital ${ }^{1}$, \\ Division of Respiratory Medicine, Atsugi Circulation Clinic ${ }^{2}$, \\ Department of Medicine, Tokai University Oiso Hospital ${ }^{3}$ \\ $\left[\begin{array}{l}\text { Received February 24, } 2014 \\ \text { Accepted April 21, } 2014\end{array}\right]$
}

The inhalation profile (flow rate, volume and pattern) from a dry powder inhaler (DPI) is crucial for the efficient delivery of medications to the bronchial airways. However, instructions regarding the inhalation profile are not always adequate. We recruited 28 volunteers who were not familiar with DPIs to simulate patients who received the first prescription of a DPI. Following verbal instructions, they inhaled from various DPIs, and we recorded the inhalation profiles as listed above. Flow-time curves were classified into 3 patterns. A: early peak followed by a linear decrement, C: trapezoid, B: between A and C. Mean ( \pm SD) peak inhaled flow rates (PIFR) and volumes were $54.3 \pm 23.5 \mathrm{~L} \cdot \mathrm{min}^{-1}$ and $1.40 \pm 0.58$ L for the Diskus $^{\circledR}, 52.8 \pm 11.5$ and $1.39 \pm 0.58$ for the Turbuhaler ${ }^{\circledR}$, and $46.0 \pm 13.4$ and $1.27 \pm 0.74$ for the Twisthaler ${ }^{\circledR}$, respectively. There were weak correlations between PIFRs and inhalation volumes. Percent of subjects attaining a PIFR $>30 \mathrm{~L} \cdot \mathrm{min}^{-1}$ was $92.9 \%\left(\right.$ Diskus $\left.^{\circledR}\right), 92.9 \%$ (Turbuhaler $^{\circledR}$ ), and $100 \%$ (Twisthaler ${ }^{\circledR}$ ), and those attaining a PIFR > $60 \mathrm{~L} \cdot \mathrm{min}^{-1}$ were $32.2 \%$ (Diskus $\left.^{\circledR}\right), 17.9 \%$ (Turbuhaler $^{\circledR}$ ), and $14.3 \%$ (Twisthaler $^{\circledR}$ ). Only a few subjects inhaled with pattern A, and most of the subjects inhaled with pattern C. In conclusion, untrained patients may inhale with suboptimal flow rates and volumes from a DPI. Inhaled flow patterns may also be poor.

Key words — dry powder inhaler, bronchial asthma, chronic obstructive pulmonary disease, peak inspiratory flow

\section{Introduction}

Inhalation therapy is currently the mainstay of treatment for bronchial asthma and chronic obstructive pulmonary disease (COPD). Most of the current devices for this purpose are dry powder inhalers (DPIs) by which the medication is inhaled through the patient's inspiratory efforts. The efficiency of a DPI depends on the inhaled flow rate and the skill in DPI use, and thus training and education in the proper use of the device are essential. Although a deep and forceful inhalation is advised in many instruction manuals (eg, http:// www.advair.com/asthma/about-advair/if-you-aretaking-advair/using-advair-diskus.html, Feb 19, 2014; http://www.symbicort.co.nz/smart/turbuhaler.php, Feb 19, 2014), forceful inhalation is somewhat ambiguous. The required flow rates from a DPI are those for drug dispersion and fine particle generation. The latter are generally higher than the former. Although the pressure change in a DPI de-aggregates the metered dose it has been estimated by flow rate through the device. ${ }^{1)}$ Several studies have suggested that patients achieve minimum peak flows both for drug dispersion as well as fine particle generation, ${ }^{2-4)}$ but most of the

* 5-1 Kandi 1-chome, Tsujido, Fujisawa, Kanagawa 251-0041, Japan 
subjects in those studies were familiar with inhalation therapy. In one study, ${ }^{5}$ a considerable number of patients with stable COPD failed to attain sufficient flow rates if they were not trained. All patients first presented with a DPI are by definition untrained, and if inspiratory flow rate is inadequate, delivery of medication may be impaired possibly resulting in the discontinuation of therapy.

Inhaled gas volume and the pattern of inhaled flow may also be strong determinants of drug delivery. ${ }^{1)}$ Although this is a complex issue, ${ }^{6}$ deep inhalation expands the airways, and thus may facilitate drug delivery to the respiratory tree. Since drug dispersion from a DPI terminates in the early phase of inhalation either in pediatric patients ${ }^{7)}$ or in adult volunteers (Kondo T, et al, unpublished data), the peak inhaled flow rate must occur very early. Therefore, the patients with obstructive lung disease should be instructed to perform a forceful, fast and sustained inhalation maneuver from DPIs. ${ }^{1)}$

In our experience, some patients referred by general physicians achieved better disease control following instruction in adequate flow rates including encouragement in faster and deeper inhalations using trainer devices. From this experience we questioned whether simple verbal instructions were adequate in those who were not familiar with DPIs. In the present study, to simulate patients receiving their first prescription of a DPI, we recruited volunteers who were not familiar with DPIs and measured their inhalation profile (peak inhaled flow rate, inhaled volume and pattern of inhaled flow) while inhaling from the device.

\section{Materials and Methods}

This study was conducted with permission of the Human Ethics Committee of Tokai University Hachioji Hospital (approved date: February 25, 2012; Approved \#: 11R-224). Subjects agreed to participate in the study after the study's purpose and procedures were explained. They also agreed not to be apprised of anticipated results since we were concerned that such knowledge might influence their inhaled flow pattern. All 28 subjects (age, 24 - 61 year-old) including a few pharmacists were not familiar with DPI use. Two were asymptomatic asthmatics and the remaining subjects were free of respiratory disease.

The recording device was an electronic system which measured pressure in the mouthpiece of each DPI via a thin tube. The pressure was converted to flow rate according to the parabolic relationship between mouthpiece pressure and inhaled flow. ${ }^{8-10)}$ Inhaled flow was then converted to volume by integration. A flow vs time curve was drawn on a small oscilloscope built into the system (Fig 1).

We analyzed inhalation profiles while subjects were inhaling from the Diskus ${ }^{\circledR}$ (Glaxo Smith Kline Inc, Middlesex, UK), Turbuhaler ${ }^{\circledR}$ (AstraZeneka Inc, London, UK) and Twisthaler ${ }^{\circledR}$ (Merck Sharp and Dohme Inc, Whitehouse Station, NJ,

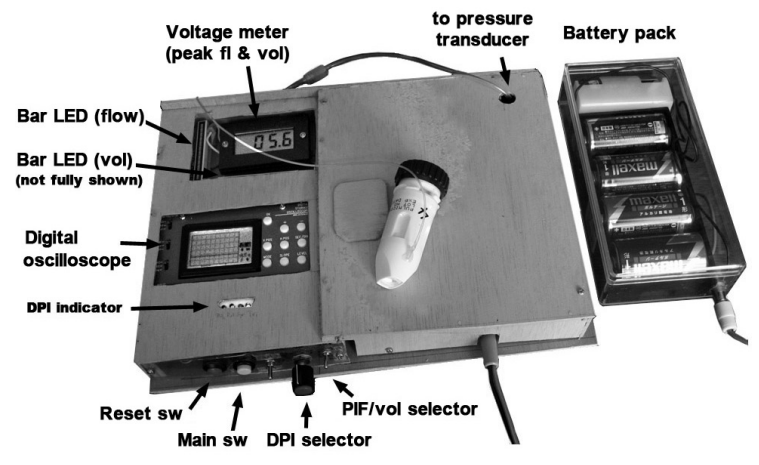

Figure 1 System appearance 
USA). All subjects were verbally instructed to inhale from the Diskus ${ }^{\circledR}$ with a maximal effort equivalent to drinking a glass of juice through a straw. This effort generates a flow of approximately $40-60 \mathrm{~L} \cdot \mathrm{min}^{-1}$. $\left.{ }^{8}\right)$ While inhaling from the Turbuhaler $^{\circledR}$ or Twisthaler ${ }^{\circledR}$, the subjects were encouraged to inhale strongly and deeply. To simulate instructions given by inexpert physicians, verbal instruction including strength, depth and speed of inhalation was given only once. From the data in our previous studies ${ }^{10)}$ resistances of DPIs were calculated as follows: Diskus ${ }^{\circledR} 22.96$, Turbuhaler $^{\circledR} 33.21$ and Twisthaler ${ }^{\circledR} 40.78(\sqrt{\mathrm{kPa}} \cdot$ $\left.\mathrm{L}^{-1} \cdot \min \cdot 10^{-3}\right)$. These values are compatible with those by Clark and Hollingworth. ${ }^{9)}$ Since the maximal inspiratory pressure of healthy human adults is approximately $7-13 \mathrm{kPa},{ }^{11,12)}$ the peak inhaled flow for Diskus ${ }^{\circledR}$ with maximal effort may reach $110-150 \mathrm{~L} \cdot \mathrm{min}^{-1}$ while those from the other DPIs may be $70-110 \mathrm{~L} \cdot \mathrm{min}^{-1}$. For this reason, we instructed that the effort to inhale from Diskus ${ }^{\circledR}$ be sub-maximal.

After one training session, inhalation strength (flow rate), depth (volume) and flow-time pattern were recorded. Flow-time curves were classified into 3 patterns based on the concept that inhaled flow rate should reach it peak during early inhalation and then decline rapidly. "PF" (peak flow) was defined as peak inhaled flow rate (PIFR) if it appeared within $0.5 \mathrm{~s}$ after the onset of inhalation (Fig 2). If PIFR appeared beyond $0.5 \mathrm{~s}$, flow at $0.5 \mathrm{~s}$ after the onset of inhalation was regarded as PF. $\mathrm{F}_{50}$ was defined as analogous to the parameter determining the convexity of the descending part of the flow-volume curve. ${ }^{13)}$ We defined $F_{50}$ as flow at mid-point between the time of PF and end of inhalation. If $\mathrm{PF} / \mathrm{F}_{50}$ was $\geq 1.5$ it was classified as type A. If $\mathrm{PF} / \mathrm{F}_{50}$ was between 1.0 and 1.49 , it was classified as type $\mathrm{B}$. The remaining curves were classified as type C (Fig 3).

We also measured the mean acceleration of flow at the ascending part of the flow-volume curve. This is defined as PIFR/Tr (rising time). Higher values of this parameter suggest an increasing inspiratory flow rate. Statistical analysis was done using a StatView 5 (SAS Institute, Cary, $\mathrm{NC}, \mathrm{USA})$.

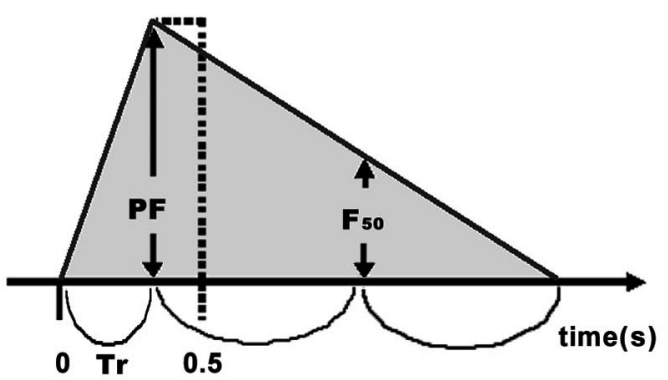

Figure 2 Definition of $\mathrm{PF} / \mathrm{F}_{50}$

PF: peak inhaled flow rate (if during first $0.5 \mathrm{~s}$ ), or flow at $0.5 \mathrm{~s}$ (peak flow appeared at $>0.5 \mathrm{~s}$ ). Tr: rising time. $\mathrm{F}_{50}$ : flow at mid-point between the time of PF and end of inhalation.
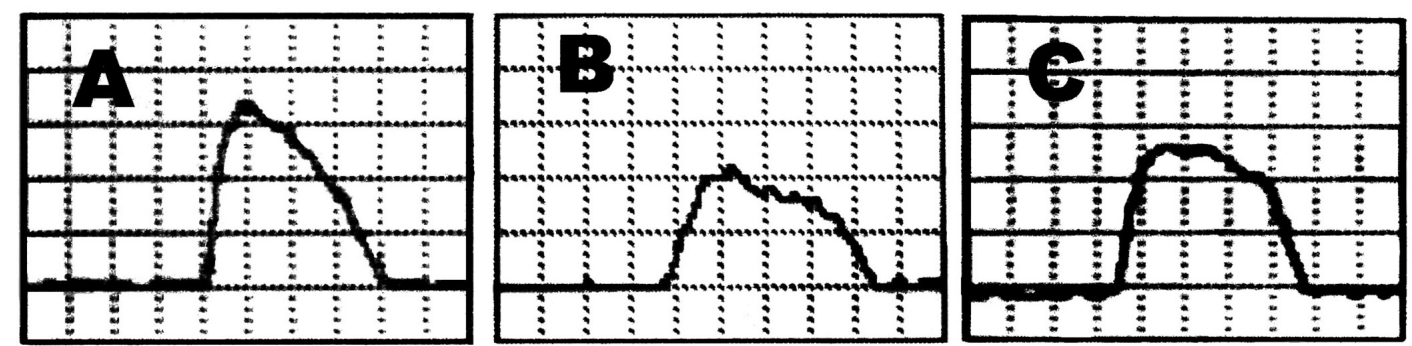

Figure 3 Representative shapes of flow-time curve patterns A: early peak followed by a linear decrement, C: trapezoid, B: between A and C. 


\section{Results}

Since there is some side stream flow using the Diskus $^{\circledast}$, we measured the resistance arising from it and found it to be $177 \sqrt{\mathrm{kPa}} \cdot \mathrm{L}^{-1} \cdot \min \cdot 10^{-3}$. This value is quite large compared with the value of 22 $\sqrt{\mathrm{kPa}} \cdot \mathrm{L}^{-1} \cdot \min \cdot 10^{-3}$ for the Diskus ${ }^{\circledast}$ itself and thus we regarded the latter value as the true resistance of the Diskus ${ }^{\circledR}$.

Figure 4 shows PIFR and volume of individual subjects. All the points were widely scattered with PIFR and volume weakly correlated.

As shown in Table 1, PIFRs (Mean \pm SD) were $54.3 \pm 23.5 \mathrm{~L} \cdot \mathrm{min}^{-1}$ for the Diskus ${ }^{\circledR}, 52.8 \pm 11.5$
$\mathrm{L} \cdot \mathrm{min}^{-1}$ for the Turbuhaler ${ }^{\circledast}$, and $46.0 \pm 13.4 \mathrm{~L} \cdot$ $\min ^{-1}$ for the Twisthaler ${ }^{\circledR}$. Mean inhaled volumes were $1.40 \pm 0.58 \mathrm{~L}$ for the Diskus ${ }^{\circledR}, 1.39 \pm 0.58$ $\mathrm{L}$ for the Turbuhaler ${ }^{\circledast}$, and $1.27 \pm 0.74 \mathrm{~L}$ for the Twisthaler ${ }^{\circledast}$. $\mathrm{R}$ and $\mathrm{p}$ values for PIFR vs volume correlations were 0.66 and $<0.01$ for the Diskus ${ }^{\circledR}$, 0.39 and 0.42 for Turbuhaler $^{\circledast}$, and 0.58 and $<$ 0.01 for the Twisthaler ${ }^{\circledR}$ respectively.

Figure 5 shows correlations between PIFR and the mean acceleration of flow of individual subjects. No correlations are apparent between them.

As shown in Table 2, percent of subjects attaining a mean peak inspiratory flow $>30 \mathrm{~L} \cdot \mathrm{min}^{-1}$ was $92.9 \%$ (Diskus $^{\circledR}$ ), $92.9 \%$ (Turbuhaler $^{\circledR}$ ), and
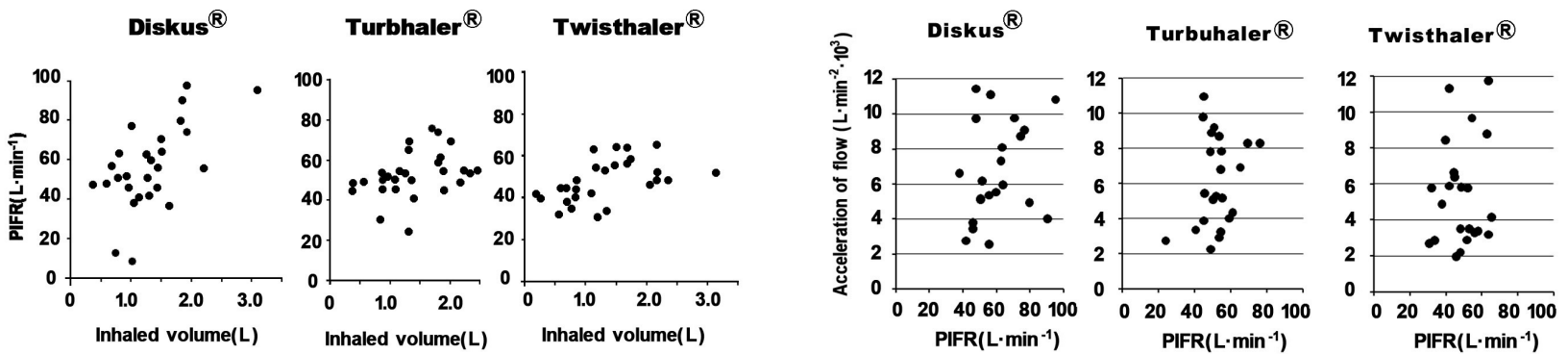

Figure 4 Correlation between peak inhaled flow rates (PIFR) and inhaled volume of individual subjects There are weak correlations between PIFR and volume as shown in Table 1. Note, most of the subjects inhaled with higher PIFRs using Diskus ${ }^{\circledR}$ and lower PIFRs using Turbuhaler ${ }^{\circledR}$ or Twisthaler $^{\circledR}$.

Figure 5 Correlation between peak inspiratory flow rates (PIFR) and the mean acceleration of flow of individual subjects

No correlations are apparent between PIFR and the mean acceleration of flow.

Table 1 Peak inspiratory flow rate (PIFR), maximal inhaled volume and their correlation

\begin{tabular}{lccc}
\hline \hline & Diskus $^{\circledR}$ & Turbuhaler $^{\circledR}$ & Twisthaler $^{\circledR}$ \\
\hline PIFR $\left(\mathrm{L} \cdot \mathrm{min}^{-1}\right)$ & $54.3 \pm 23.5$ & $52.8 \pm 11.5$ & $46.0 \pm 13.4$ \\
Max inhaled volume (L) & $1.40 \pm 0.58$ & $1.39 \pm 0.58$ & $1.27 \pm 0.74$ \\
Correlation parameters for & $\mathrm{R}=0.66, P<0.01$ & $\mathrm{R}=0.39, P=0.42$ & $\mathrm{R}=0.58, P<0.01$ \\
PIFR vs volume relationship & & & \\
\hline
\end{tabular}

Mean \pm SD; R, correlation coefficient of PIFR vs Maximal inhaled volume.

Table 2 Percent of subjects exceeding a threshold flow and volume

\begin{tabular}{lccc}
\hline \hline & Diskus $^{\circledR}$ & Turbuhaler $^{\circledR}$ & Twisthaler $^{\circledR}$ \\
\hline MIFR $>30 \mathrm{~L} \cdot \mathrm{min}^{-1}$ & 92.9 & 92.9 & 100 \\
MIFR $>60 \mathrm{~L} \cdot \mathrm{min}^{-1}$ & 32.2 & 17.9 & 14.3 \\
Max inhaled volume $>1.0 \mathrm{~L}$ & 67.9 & 71.4 & 60.7 \\
\hline MIFR mean inhaled flow rate & & &
\end{tabular}


Table 3 Inhaled flow profiles from the dry powder inhaler (DPI)

\begin{tabular}{|c|c|c|c|c|c|c|c|c|c|c|c|c|c|c|c|c|c|c|c|c|c|c|c|c|c|c|c|c|}
\hline Subject \# & 1 & 2 & 3 & 4 & 5 & 6 & 7 & 8 & 0 & 10 & 11 & 12 & 13 & 14 & 15 & 16 & 17 & 18 & 19 & 20 & 21 & 22 & 23 & 24 & 25 & 26 & 27 & 28 \\
\hline Diskus $^{\circledR}$ & A & B & B & & & $\mathrm{C}$ & B & A & $C$ & B & $r$ & O & $\mathrm{C}$ & $C$ & $\mathrm{~B}$ & $\mathrm{C}$ & B & B & A & B & $C$ & $\mathrm{C}$ & ( & $\mathrm{C}$ & $\mathrm{C}$ & $C$ & $\mathrm{C}$ & $C$ \\
\hline Turbuhaler $^{\circledR}$ & B & $\mathrm{C}$ & C & $\mathrm{C}$ & ( & $C$ & $\mathrm{C}$ & A & $\mathrm{C}$ & $\mathrm{C}$ & $\mathrm{C}$ & A & B & $\mathrm{C}$ & B & $C$ & B & & $\mathrm{B}$ & $\mathrm{C}$ & $\mathrm{C}$ & $\mathrm{C}$ & & C & 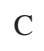 & - & $\mathrm{C}$ & \\
\hline Twisthaler ${ }^{\circledR}$ & & A & $\mathrm{C}$ & $\mathrm{C}$ & & $\mathrm{C}$ & $\Omega$ & A & D & A & $\mathrm{C}$ & $\mathrm{C}$ & $\Omega$ & $\Omega$ & $D$ & $\mathrm{C}$ & $\mathrm{C}$ & & $C$ & $A$ & B & $\mathrm{C}$ & $\mathrm{C}$ & $\mathrm{C}$ & $\mathrm{C}$ & $\mathrm{C}$ & $C$ & $C$ \\
\hline
\end{tabular}

A: early peak followed by linear decrement, C: trapezoid, B: between A and C.

$100 \%$ (Twisthaler $\left.{ }^{\circledR}\right)$. Percent of subjects attaining a mean peak inspiratory flow $>60 \mathrm{~L} \cdot \mathrm{min}^{-1}$ was $32.2 \%$ (Diskus $^{\oplus}$ ), $17.9 \%$ (Turbuhaler ${ }^{\circledast}$ ), and $14.3 \%$ (Twisthaler ${ }^{\circledast}$ ).

Table 3 shows the inhalation pattern of each subject. Only a few subjects inhaled with type A, and most of the subjects inhaled with a type $\mathrm{C}$ pattern. If type A and B had not been separately defined, the inhalation pattern of subjects was almost the same irrespective of the DPI.

\section{Discussion}

The inhaled flow rate is crucial for sufficient delivery of inhaled medications to the airways. Thus education and training regarding inhaled flow is important especially in patients first using a DPI. However, studies on patients untrained in DPI use are scarce. ${ }^{5,14)}$ The minimum PIFR for drug dispersion from a DPI is thought to be 30 to $60 \mathrm{~L} \cdot \mathrm{min}^{-1}$. Usually this flow rate is not sufficient to generate fine particles capable of arriving at the lower airways. ${ }^{15)}$ Since narrowing of the small airways is the major pathophysiologic change in COPD and airway inflammation in bronchial asthma also involves small airways, ${ }^{16)}$ the delivery of medication to small-sized airways in inhalation therapy is desirable, but currently unachievable with current DPIs in clinical practice. ${ }^{17)}$ Because particles of $4-5 \mu \mathrm{m}$ deposit primarily in the bronchial/ conducting airways, ${ }^{1)}$ most DPIs are designed to generate particles of this size. Mini- mum PIFR for fine particle dispersion has been reported as $30-60 \mathrm{~L} \cdot \min ^{-1}{ }^{18-20)}$ for Diskus ${ }^{\oplus}$, and $60 \mathrm{~L} \cdot \min ^{-1}{ }^{18-21)}$ for Turbuhaler ${ }^{\circledast}$. Yang et $a l^{22)}$ reported that $39.9 \%$ of dispersed particles from Twisthaler $^{\circledast}$ were less than $6.5 \mu \mathrm{m}$ in diameter during evacuation with $60 \mathrm{~L} \cdot \mathrm{min}^{-1}$. Reported PIFR through a DPI in patients with bronchial asthma or COPD was $63.7^{2)}-118 \mathrm{~L} \cdot \mathrm{min}^{-13)}$ for Diskus $^{\circledR}$ and $53.5^{4)}-88^{3)} \mathrm{L} \cdot \mathrm{min}^{-1}$ for Turbuhaler ${ }^{\circledR}$. These values seem sufficient to generate fine particles. However, most of the subjects in these studies were familiar with DPIs. The present study reveals that untrained subjects inhale with considerably lower flow rates even after verbal instruction. This has also been noted in a study ${ }^{5}$ in which $4.9 \%$ of untrained COPD patients inhaled from Diskus ${ }^{\circledast}$ with a flow $<30 \mathrm{~L} \cdot \mathrm{min}^{-1}$, and $14.2 \%$ inhaled from Turbuhaler ${ }^{\circledast}$ with a flow $<30$ $\mathrm{L} \cdot \mathrm{min}^{-1}$. In our study, only $17.9 \%$ of the subjects inhaled with $>60 \mathrm{~L} \cdot \mathrm{min}^{-1}$ with Turbuhaler ${ }^{\circledast}$ use and $14.3 \%$ with Twisthaler ${ }^{\circledast}$ use. These findings are of additional interest ${ }^{5,9)}$ because particles dispersed from these devices are sufficiently small to minimize oropharyngeal impact, and patients may not perceive whether the medication has actually been inhaled. As a result they may discontinue their inhalation therapy. Low resistance devices such as Diskus ${ }^{\circledR}$ may have advantages in drug dispersion and fine particle generation but have a tendency to produce adverse oropharygeal effects. In contrast, high resistance devices may not generate sufficiently high flow even with the stron- 
gest effort. Banno et $a l^{23)}$ reported that PIFR was an important determinant in the choice of a suitable DPI for the individual patient.

With regard to methodology one may question whether the order of the four DPIs had any effects on inhalation pattern or parameters. In our recent study, we found that both flow pattern and parameters of DPI inhalation were not significantly different whether starting with Diskus ${ }^{\circledast}$ or Trubuhaler ${ }^{\circledR}$ (personal communication). One may also question whether fine particle dispersion predicted by studies on healthy subjects is applicable to patients with asthma or COPD. Since fine particle dispersion depends on inhaled flow pattern and intensity, if these are the same the subject's health status should not influence the results. Finally, although a few pharmacists were included in our subjects the data obtained from them resembled those obtained from the others ${ }^{24)}$ so that a subject's professional status did not appear to influence the results.

Two studies reported that a considerable number of patients currently using a DPI inhaled with inadequate PIFR ${ }^{5,14)}$ with flow rates becoming satisfactory after verbal instruction ${ }^{5)}$ or training with In-Check ${ }^{\circledast}{ }^{14)}$ Similar studies have reported that many patients, whether children ${ }^{25)}$ or adults, ${ }^{26)}$ failed to use their DPI properly so that verbal instruction alone may not always be sufficient in those currently using a DPI. Our results suggest that verbal instruction may also be insufficient in subjects who are unfamiliar with a DPI. Hence the initial instruction using teaching aids such as trainer devices or In-Check ${ }^{\circledast}$ may be needed in addition to verbal instructions.

Inhaled volumes from a DPI in patients with asthma or COPD have been reported as $2.8^{27)}-3.1$ $\mathrm{L}^{28)}$ for Diskus ${ }^{\circledR}$ and $2.4^{27)}-2.9 \mathrm{~L}^{28)}$ for Turbuhaler ${ }^{\circledR}$. Our estimated inhaled volumes in the subjects un- familiar with a DPI were smaller than these values. Since the predicted inspiratory capacity in healthy humans is $3-4 \mathrm{~L}$, our subjects did not inhale maximally using each DPI. Lung inflation widens small as well as large bronchi. ${ }^{29)}$ However, the extent to which bronchial dilation with deep lung inflation facilitates drug delivery awaits further studies.

For effective drug dispersion from a DPI, the timing of the PIFR is also important. Bisgaard et $a l^{7)}$ recorded inhalation pressure against time in asymptomatic asthmatic children while inhaling from a DPI, and they then measured the emission of the aerosol cloud from a DPI with the simulated inhalation profile. They found that the aerosol was released 0.2 - $0.3 \mathrm{sec}$ before maximal inhalation pressure was reached (ie before PIFR) using Diskus $^{\circledast}$ or Turbuhaler ${ }^{\circledast}$. In addition, Everard $e t$ $a l^{30)}$ compared the effect of faster and slower inhalation on the incidence of fine particles in the dispersed drug. They found that considerable fine particle dispersion was achieved only with rapid inhalation. These findings suggest that attaining PIFR very early is beneficial for drug dispersion from a DPI. In contrast slow inhalation is preferred following drug dispersion because many particles are otherwise trapped in the oropharynx. ${ }^{31)}$ In our study we classified inhalation flow patterns as A, B and C type. We found only a small number of subjects inspired with the most beneficial flow pattern-type A. Furthermore, there were some low mean acceleration of flows even with high inspiratory flow rates as shown in Fig 4. This flow pattern even with high PIFR is inappropriate with regard to drug dispersion. Therefore we propose that instruction for DPI inhalation should include the term "fast" as well as forceful and deep. Thus, instruction regarding flow pattern is also necessary for optimal DPI usage. Although 
a few devices ${ }^{28,32)}$ can provide visual feedback of inhalation profiles, their large size and need for an electric power supply are impractical for daily clinical practice. We recently developed a device that displays a subjects' inspiratory flow vs time pattern $(12.5 \times 8.0 \times 3.5 \mathrm{~cm}$ in size, $300 \mathrm{~g}$ in weight) as well as their PIFR, time to reach PIFR and inspiratory volume. This may be one example a visual feedback trainer. ${ }^{33)}$

Although many physicians focus their attention in inhalation therapy on the strength of inhalation and efficacy of the drug, the inhalation profile is also very important. The results of the present study suggest that verbal instruction by itself is insufficient to achieve an appropriate inhalation profile using a DPI in subjects who are unfamiliar with the device. Visual feedback concerning peak flow rate, inhaled volume and flow pattern would be helpful.

\section{Acknowledgements}

The authors gratefully appreciate Dr Stanley M Cassan for his critical review of this manuscript, and Miss Takahari Y and Miss Iwao K for their excellent technical assistance in the study.

\section{References}

1) Laube BL, Janssens HM, de Jongh FHC, Devadason SG, Dhand R, Diot P, Devadason SG, Dhand R, Diot P, Everard ML, Horvath I, Voshaar T, Chrystyn H, What the pulmonary specialists should know about new inhalation therapies, Eur Respir J, 2011, 37, 1308-1331.

2) Weiner PP, Weiner M, Inspiratory muscle training may increase peak inspiratory flow in chronic obstructive pulmonary disease, Respiration, 2006, 73, 151-156.

3) Van der Palen J, Peak inspiratory flow through Diskus and Turbuhaler, measured by means of a peak inspiratory flow meter (In-Check dial), Respir Med, 2003, 97, 285-289.

4) Brunell PKP, Small T, Doig S, Johal B, Jenkins R, Gibson GJ, Ex-vivo product performance of Diskus and Turbuhaler inhalers using inhalation profiles from patients with severe chronic obstructive pulmonary disease, Respir Med, 2001, 95, 324-330.

5) Al-Showair RAM, Tarsin WY, Assi KH, Pearson SB, Chrysyn H, Can all patients with COPD use the correct inhalation flow with all inhalers and does training help? Respir Med, 2007, 101, 2395-2401.

6) Brown RH, Mechanism of limited airway dimension with lung inflation, Pulm Pharmcol Therapeut, 2007, 20,118-125.

7) Bisgaard H, Klug B, Sumby BS, Burnell PK, Fine particle mass from Diskus inhaler and Turbuhaler inhaler in children with asthma, Eur Respir J, 1998, 11, 1111-1115.

8) Kanabuchi K, Kondo T, Tanigaki T, Tajiri S, Hayama N, Takahari Y, Iwao K, Minimal inspiratory flow from dry powder inhalers according to biphasic model of pressure vs flow relationship, Tokai J Exp Clin Med, 2011, 36, 1-4.

9) Clark AR, Hollingworth AM, The relationship between powder inhaler resistance and peak inspiratory conditions in healthy volunteers-implications for in vitro testing, J Aerosol Med, 1993, 6, 99-110.

10) Kondo $T$, Tanigaki $T$, Tazaki G, Watanabe H, Ishii H, Tsunoda $\mathrm{T}$, Uruma $\mathrm{T}$, The relation between inspiratory pressure and flow through dry powder inhaler available in Japan, Jpn J Allergol, 2010, 59, 950955.

11) Black LF, Hyatt RE, Maximal respiratory pressure: normal values and relationship to age and sex, $A m$ Rev Respir Dis, 1969, 99, 696-702.

12) Wilson SH, Cooke NT, Edwards RHT, Spiro SG, Predicted normal values for maximal respiratory pressure in Caucasian adults and children, Thorax, 1984, 38, 535-538.

13) Takishima T, Sasaki T, Takahashi K, Sasaki H, Nakamura T, Direct-writing recorder of the flow-volume curve and its clinical application, Chest, 1972, 61, 262-266.

14) Melani AS, Bracci LS, Rossi M, Reduced peak inspiratory effort through the Diskus and the Turbuhaler due to mishandling is common in clinical practice, Clin Drug Invest, 2005, 25, 543-549.

15) MacIntire NR, Aerosol consensus statement, Chest, 1991, 100, 1106-1109.

16) Tulic MK, Christodoulopoulos P, Hamid Q, Small 
airway inflammation in asthma, Respir Res, 2001, 2, 333-339.

17) Usmani OS, Unravelling the small airways: structure-function-treatment relationship in asthma and COPD, Respiration, 2012, 84, 1-3.

18) Hill LS, Slater AL, A comparison of the performance of two modern multidose dry powder asthma inhalers, Respir Med, 1998, 92, 105-110.

19) Palander A, Matila T, Karhu M, Muttonen E, In vitro comparison of three salbutamol-containing multidose dry powder inhalers: Buventol Easyhaler, Inspiryl Turbuhaler and Venetolin Diskus, Clin Drug Invest, 2000, 20, 25-33.

20) Prime DJ, Grant AC, Slater AL, Woodhouse RN, A critical comparison of the does delivery characteristics of four alternative inhalation devices delivering salbutamol: pressurized metered dose inhaler, Diskus inhaler, Diskhaler inhaler and Turbuhaler inhaler, $J$ Aerosol Med, 1999, 12, 75-84.

21) Malton A, Sumby BS, Dandiker Y, A comparison of in-vitro drug delivery from salbutamol Diskus and terbutaline Turbohaler inhalers, J Pharm Med, 1996, 6, 35-48.

22) Yang TT, Li S, Wyka B, Kenyon MS, Drug delivery performance of the mometasone furonate dry powder inhaler, J Aerosol Med, 2001, 14, 487-494.

23) Banno M, Mase H, Shimada I, Nakamura K, Selecting inhalation devices based on inspiratory flow rate, Jpn J Pharm Health Care Sci, 2007, 33, 451-456.

24) Kondo T, Tanigaki T, Watanabe H, Tazaki G, Uruma $\mathrm{T}$, Tsunoda T, Tajiri S, Profiles of inspiratory flow from dry powder inhalers, Jpn J Allergol, 2012, 62 $(3,4), 485$.

25) Kampus AWA, van Ewijk B, Roorda RJ, Brand PLP,
Poor inhalation technique, even after inhalation instructions, in children with asthma, Pediatr Pulmonol, 2000, 29, 39-42.

26) Ovchinikova L, Smith L, M Bosnic-Anticevich S, Inhaler technique maintenance: Gaining an understanding from the patient's perspective, J Asthma, 2011, 48, 616-624.

27) Tarsin WY, Pearson SB, Assi KH, Chrystyn H, Emitted dose estimates from Seretide Diskus and Symbicort Turbuhaler following inhalation by severe asthmatics, J Aerosol Med, 2006, 19, 131-137.

28) Broeders MEAC, Molema J, Vemue NA, Folgering HTM, In check dial: accuracy for Diskus and Turbuhaler, Internat J Parmaceut, 2003, 252, 275280.

29) Huges JMB, Hoppin FG, Mead J, Effect of lung inflation on bronchial length and diameter in excised lungs, J Appl Physiol, 1972, 32, 25-35.

30) Everard ML, Devadason SG, Le Souef PN, Flow early in the inspiratory manoeuvre affects the aerosol particle size distribution from a Turbuhaler, Respir Med, 1997, 91, 624-628.

31) Usmani OS, Biddiscombe MF, Barnes J, Regional lung deposition and bronchodilator response as a function of beta2-agonist particle size, Am J Respir Crit Care Med, 2005, 172, 1497-1504.

32) Cegla UH, Pressure and inspiratory flow characteristics of dry powder inhalers, Respir Med 2004, 98 (suppl A), S22-S28.

33) Kondo T, Hibino M, Tanigaki T, Morita N, Fukuzaki M, Ohe M, Akazawa K, Hikino K, Shimizu T, Tajiri $\mathrm{S}$, A device to display inspiratory profile from DPIs and its potential use, Jpn J Allergol, 2013, 62 (9,10), 1298. 